\title{
Pressurized hole as a Stress Reducing feature
}

\author{
S. B. Tuljapure ${ }^{1}$, S. S. Sarawade ${ }^{2}$, N.A. Sayyed Md. Shoaib ${ }^{3}$ \\ ${ }^{1}$ (Mechanical Engineering Department, Walchand Institute of Technology, SolapurUniversity, Solapur) \\ ${ }^{2}$ (Mechanical Engineering Department, M.E.S. College of Engineering, S.P.P.U., Pune) \\ ${ }^{3}$ (Student- M.E. - Mechanical Engg., Walchand Institute of Technology, SolapurUniversity, Solapur)
}

\begin{abstract}
In many structures, cracks may appear during manufacturing process or in service. Stress intensity factor is used in fracture mechanics to more accurately predict the stress state (stress intensity) near the tip of the crack caused by remote load or residual stresses. In this work a rectangular plate with central hole \& two cracks emanating from his hole is analyzed for remote tensile loading. Stress Intensity Factor is determined for this configuration using finite element based software ANSYS. This value is compared with the one obtained by analytical method. Then hole as a stress reducing feature is studied. The effect of hole location, hole size on the stress intensity factor is studied. Feasibility of pressurized hole as a stress reducing feature is studied for the best hole location \& size obtained earlier. Further variation in the pressure was done to study effect of pressurized hole.
\end{abstract}

Keywords - finite element analysis, hole, pressurized hole, Stress Intensity Factor, Stress reducing feature

\section{INTRODUCTION}

Fracture Mechanics is the field of mechanics concerned with the study of the propagation of cracks in materials. It uses methods of analytical solid mechanics to calculate the driving force on a crack and those of experimental solid mechanics to characterize the material resistance to fracture. Stress intensity factor, $\mathrm{K}$, is used in fracture mechanics to more accurately predict the stress state (stress intensity) near the tip of the crack caused by remote load or residual stresses. It is theoretical construct applicable to a homogeneous elastic material and is useful for providing failure criteria for brittle materials. The stress intensity factor remains finite and provides a basis for determining the critical load. If the value of SIF is less than the toughness of the material, the structure is safe. If SIF value is more than the toughness of material, the structure fails. Typical Stress Intensity Factor Reduction Techniques used by earlier researchers are: Strip or patch repair method, Artificial crack closure by crack filling, Welding repair, Hole drilling.

In this work, finite element analysis of a cracked plate is done. Initially a hole is used as a stress reducing feature. Then the effect of pressure applied in this hole is studied.

\section{LITERATURE REVIEW}

Miloud Souiyah, Abdulnaser Alshoaibi. et al [1] considered a rectangular plate with crack starting from a circular hole and double edge notched plate. Both geometries were in tensile loading and under mode-I conditions. In this paper a displacement extrapolation technique was employed particularly to predict the crack propagations direction and to calculate SIFs and validated with the relevant numerical and analytical results obtained by other researcher. Xiangqiao Yan [2] studied the stress intensity factors (SIFs) of cracks emanating from a rhombus hole in a rectangular plate subjected to internal pressure by means of the displacement discontinuity method with crack-tip elements (a boundary element method) proposed by the author. Moreover, an empirical formula of the SIFs of the crack problem was presented and examined. It was found that the empirical formula is very accurate for evaluating the SIFs of the crack problem. Junping Pu [3] studied a Boundary value problem of a plate with crack and defect such as the circular and/or elliptical holes. This kind of problem was suitable for solving by boundary element method with its higher precision. The sub-region method was used in this work. A center cracked plate subjected to remote tensile and shear loading was studied numerically. Levend Parnas and Omer G. Bilir [4] calculated Stress Intensity Factor by experimental procedures using strain gages. In this method, cracks were opened at the tip of crack starter slot on the standard compact tension test specimens by using Electrical Discharge Machining (EDM) and Wiring Discharge Machining (WDM). Strain gage data from the crack tip region were used to calculate stress intensity factors. But the values obtained were on lower side. This was partly due to unavoidable deformations in the adhesives used to fasten the strain gages to the specimen. This might be also due to the use of the relatively long strain gages, local yielding and three-dimensional effects and limited regions for strain gauge. 
G.A. Papadopoulos, B. Badaloukaandj [5] used different methods to reduce S.I.F. at the crack tip. The methods were Strip or patch repair method, Artificial crack closure by crack filling and Welding repair.

Strip or patch repair method: Strip or patch repair is method of repairing cracked structural components. The basic principle of the method is to adhesively bond a strip or patch over the cracked area in order to restore the load carrying capacity of the structure. The method of bonded patch repair presents many advantages because no fastener holes for application are needed, and therefore, no micro cracks develop, a uniform stress transfer results, no drilling is necessary, and the time and cost for the repair are substantially reduced.

Artificial crack closure by crack filling: The plasticity-induced crack closure effect discovered by Elber was reducing the stress intensity range of a load cycle, resulting in retarded crack growth. When crack closure occurs, the crack closes upon unloading before the applied load reaches zero. When a material is inserted between the two faces of a fatigue crack and the filler material is inelastic enough to substantially resist compression, the crack has effectively been filled with a wedge. As a consequence, the crack will be 'closed' at an earlier stage during the unloading phase of the load cycle and open up at a later stage of the loading phase.

Welding repair: Conventional fusion welding can be applied to restore structural strength lost due to a fatigue crack. It can be done by adding weld material to close a grind-out crack area or by welding a metal patch to the parent structure to overlay the grind-out However, precautions need to be taken to minimize residual stresses and stress corrosion cracking Domazet investigated repairs to a fatigue crack in an $\mathrm{AlCuMg}_{2}$ alloy by grinding out the crack and applying an X-form weld and also, by welding a patch of the same material over the crack.

S.T. Pinho, H.B. Martins, P.P. Camanho, M.H. Santare [6] used stop drill method.

Stop Hole Drill Method: The easiest way to reduce the stress intensity at crack tips is to drill a hole or stop hole at the crack tip. The hole takes away the stress singularity at the crack tip and so significantly reduces the stress concentration in the crack area. If crack tip misses means that creates the risk.

Another way of applying stop holes is by drilling holes at slightly ahead of the visible crack tip, along the expected crack growth path. Once the crack reaches the hole, the crack will need to reinitiate. This reinitiating process will cause crack growth retardation. A larger hole will reduce the stress concentration factor of the crack/hole combination more and therefore larger holes will yield greater fatigue life extension.

The overall crack growth life extension by using stop holes without cold expansion is small, however, because the presence of the holes can initially speed up the crack growth and when the crack reaches the hole, this hole becomes part of the crack, and thus extends the crack.

\section{Crack Flank Holes Method}

Certain distance above and below (and in line with) the crack tip, the so-called 'crack flank holes'. Applying crack flank holes close to the crack tip reduces the stress intensity at the crack tip. It has been indicated that crack flank holes can reduce the stress concentration at the crack tip (Fig. 1), and also in combination with a stop hole (Fig.2). If the holes are not positioned too far away from the crack tip, the crack will grow towards one or both of the holes and it will then have to reinitiate before it can start growing again. If the crack flank holes are drilled under an angle to the plane of the plate, the hole might fail to capture the entire crack tip and in this way sustain a relatively high crack growth rate. This risk can be reduced by applying the holes closer to the crack tip, at the cost of less effective retardation.

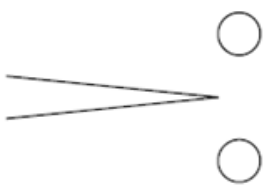

Fig. 1 Schematic of a crack tip with two crack flank hole

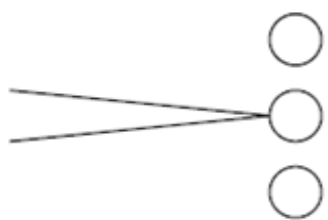

Fig.2 Schematic of a crack tip with a stop hole and two crack flank holes

\section{$>$ The Cold Hole-Expansion Process}

The effectiveness of stop-drilling as a crack growth retardation method can be increased significantly by cold expansion of the hole. Generally, the expansion of the hole is achieved by pulling a device that is larger than the hole through the existing hole, thereby radially expanding the hole beyond the point where plastic 
deformation (flow) of the material starts. Upon removal of the pulling device, the elastic material around the plastic zone springs back and creates biaxial residual stresses around the hole.

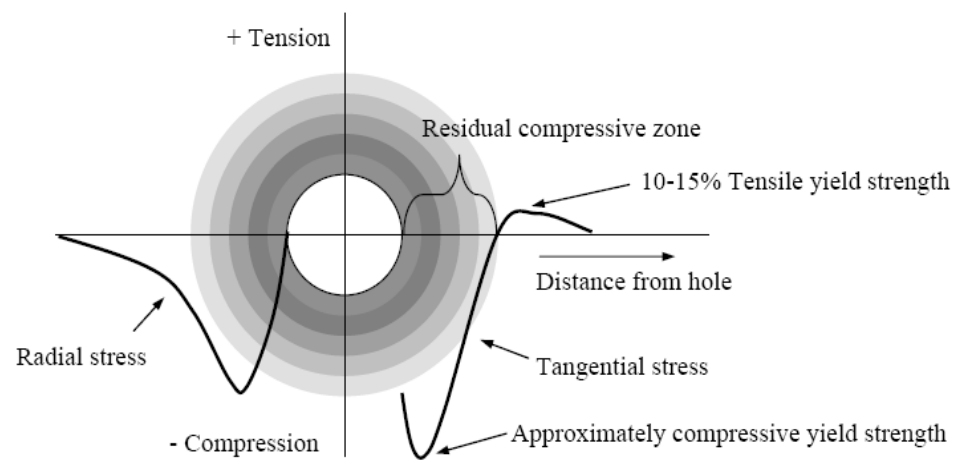

Fig. 3 Schematic sketch distribution of a stress around a cold expanded hole

The pulled device is sometimes ball shaped, but it is usually a tapered mandrel. The degree of cold expansion, Io, is commonly expressed as

$$
\mathrm{Io}=\mathrm{D}-\mathrm{d} / \mathrm{d}
$$

Where, $\mathrm{D}$ is the largest diameter of the pulled device and $\mathrm{d}$ the initial diameter of the hole. As a result of the process, the residual tangential and radial stress distributions around the hole have been found to be as schematically depicted in Fig. 3.

\section{Cold Expansion Process}

The most widely used variant of cold hole-expansion in the aviation industry is the split-sleeve cold expansion process, depicted in Fig. 4

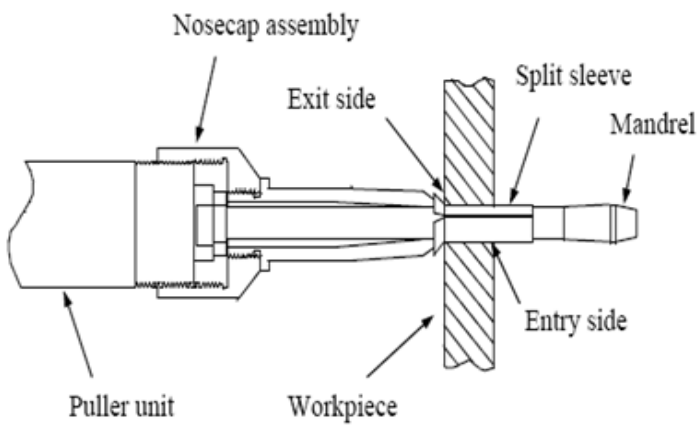

Fig. 4 Set up of cold expansion process

This was invented by the Boeing Company in the late 1960's. The principle behind this is to expand the hole from one side by pulling a tapered mandrel through a lubricated sleeve that has been inserted into the hole. The combination of mandrel plus sleeve has a greater diameter than the hole, which will expand the hole radially when the mandrel is pulled through. The disposable sleeve reduces the mandrel pull force, it ensures correct radial expansion and it prevents damage to the hole.

\section{ANALYTICAL APPROACH}

For the present work, a plate with central hole \& two cracks emanating from this is taken. The plate is under remote tensile loading. The arrangement is shown in Fig. 5. 


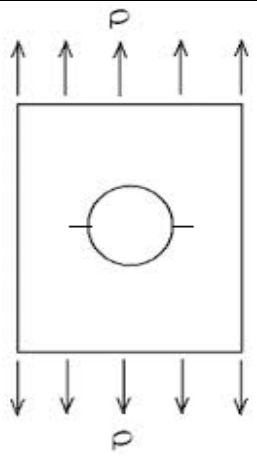

Fig. 5 A rectangular plate with cracks emanating from hole

Crack length of $5 \mathrm{~mm}$ was considered for this study. The normal value of S.I.F. for this geometry under a remote tensile stress of $200 \mathrm{MPa}$ is calculated using Boundary Correction Factors available in the literatures. $\mathrm{BCF}$ is 1.0168 [7].

$$
\begin{aligned}
\mathrm{K}_{1} & =\mathrm{F}(\lambda, \mathrm{a} / \mathrm{R}) \sigma^{\sqrt{\pi \cdot a}}, \\
& =1.0168 \times 200 \mathrm{X} \sqrt{3.14 \times 25} \\
& =1802.23 \quad \mathrm{~N}-\mathrm{mm}^{-3 / 2}
\end{aligned}
$$

Stress Intensity Factor $\left(\mathrm{K}_{1}\right)$ is to be determined by the finite element analysis \& compared with above analytical solution.

\section{FINITE ELEMENT ANALYSIS}

Finite element analysis is done using ANSYS software. Considering symmetry only quarter model is prepared. Quadrilateral element with mid-side nodes is used for meshing. Fig. 6 shows meshed model with load condition \& boundary condition. Also the deformed shape \& Von Mises stresses are shown in this figure.

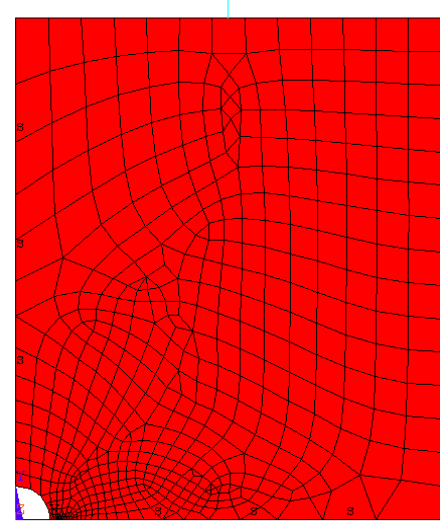

a) Meshed model with load \& boundary conditions

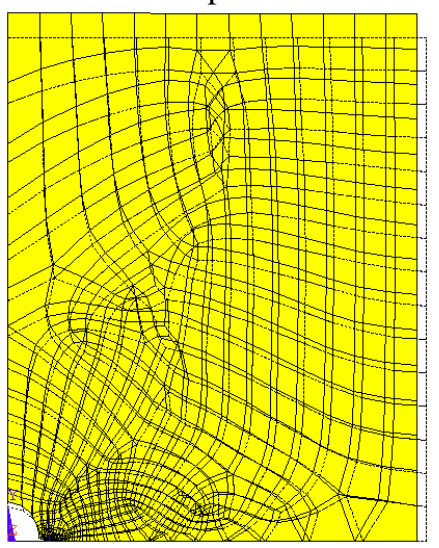

b) Deformed shape

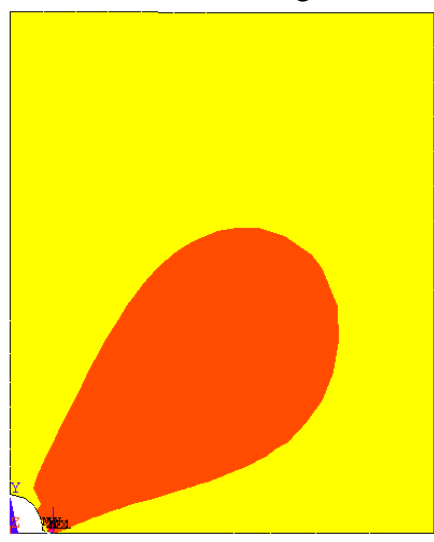

c) Von Mises Stresses

Fig. 6 Details of Finite element analysis

In fig. 6 a) applied symmetric boundary conditions about vertical \& horizontal sides can be observed along with meshed structure. Load condition can also be observed. In this case no stress reducing feature is used. Fig. 6 b) shows deformed shape of the plate. The Von Mises stress can be observed in the Fig. 6 c)

The value of the stress intensity factor obtained by 'ANSYS' software is $1834.4 \mathrm{~N} \mathrm{~mm}^{-3 / 2}$

Percentage Error $=\left\{\left(\mathrm{K}_{\text {Ansys }}-\mathrm{K}_{\text {Analytical }} / \mathrm{K}_{\text {Analytical }\}} \times 100\right.\right.$

$$
\begin{aligned}
& =(1834.4-1802.23) \times 100 / 1802.23 \\
& =1.785 \%
\end{aligned}
$$

The error in the finite element solution is determined by comparing the same with analytical solution obtained by using Newman's equation. The error is $1.764 \%$ which is within acceptable range.

\section{Hole as a Stress Reducing Feature:}

Further analysis is done with FEM by introducing the stress reducing feature hole to different location and radius of hole. The output of SIF is as shown in below Table 1. The centre of plate is taken as origin. 
Table 1 Trial of reduction of S.I.F. for remote tensile loading

\begin{tabular}{|c|c|c|c|c|}
\hline $\begin{array}{c}\text { Sr. } \\
\text { No }\end{array}$ & $\begin{array}{c}\mathbf{X} \text { Coordinate } \\
(\mathbf{m m})\end{array}$ & $\begin{array}{c}\text { Y Coordinate } \\
(\mathbf{m m})\end{array}$ & $\begin{array}{c}\text { Radius of Hole } \\
(\mathbf{m m})\end{array}$ & $\begin{array}{c}\text { S.I.F } \\
\left(\mathbf{N}-\mathbf{m m}^{-3 / 2} \mathbf{2}\right)\end{array}$ \\
\hline 1 & 30 & 10 & 5 & 2211.3 \\
\hline 2 & 30 & 15 & 5 & 1964.4 \\
\hline 3 & 30 & 50 & 5 & 1814.17 \\
\hline 4 & 30 & 60 & 5 & 1812.8 \\
\hline 5 & 30 & 65 & 5 & 1812.3 \\
\hline 6 & 30 & 70 & 5 & 1815.4 \\
\hline 7 & 30 & 75 & 5 & 1815.1 \\
\hline
\end{tabular}

As there is very less reduction in S.I.F. at higher values of vertical distance, the hole size is now increased to check further reduction of S.I.F. Table 2 summarizes the variation in S.I.F due to variation in the stress reducing hole size.

Table 2 Effect of hole size on the values of S.I.F.

\begin{tabular}{|c|c|c|c|c|}
\hline $\begin{array}{c}\text { Sr. } \\
\text { No }\end{array}$ & $\begin{array}{c}\mathbf{X} \text { Coordinate } \\
(\mathbf{m m})\end{array}$ & $\begin{array}{c}\text { Y Coordinate } \\
(\mathbf{m m})\end{array}$ & $\begin{array}{c}\text { Radius of Hole } \\
(\mathbf{m m})\end{array}$ & $\begin{array}{c}\text { S.I.F } \\
\left(\mathbf{N}^{-\mathbf{m m}} \mathbf{- 3}^{-3}\right)\end{array}$ \\
\hline 1 & 30 & 65 & 5 & 1812.3 \\
\hline 2 & 30 & 65 & 10 & 1752.9 \\
\hline 3 & 30 & 65 & 20 & 1517.8 \\
\hline $\mathbf{4}$ & $\mathbf{3 0}$ & $\mathbf{6 5}$ & $\mathbf{2 5}$ & $\mathbf{1 2 8 3 . 9}$ \\
\hline
\end{tabular}

The fig.7 a) shows use of hole as a stress reducing feature is done. Fig. 7 b) shows the deformed shape of the plate. In fig. $7 \mathrm{c}$ ) the distribution of the stresses can be observed.

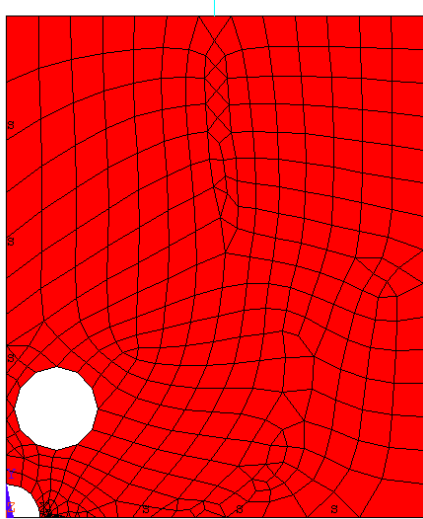

a) Meshed model with load \& boundary conditions

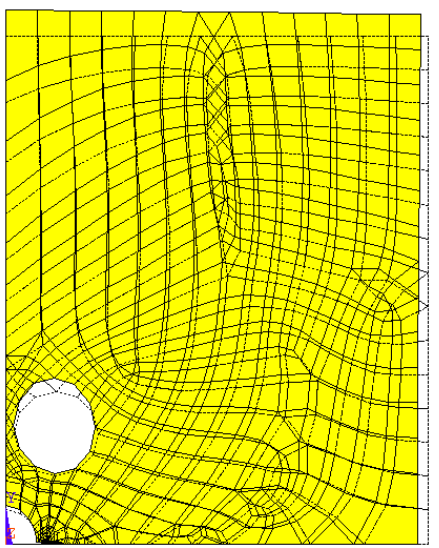

b) Deformed shape

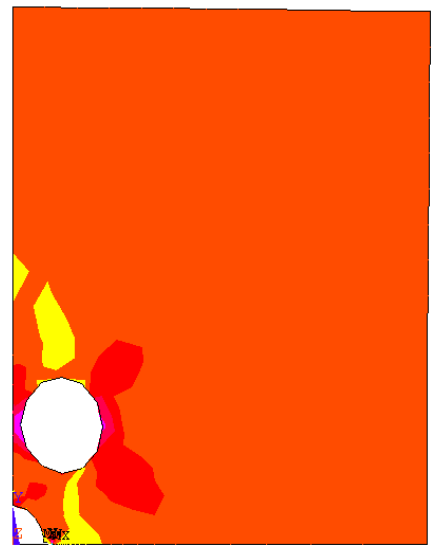

c) Von Mises Stresses

Fig.7 Hole as stress reducing feature

This distribution is different from the one without stress reducing feature. Here stresses are lesser as compared to the one without stress reducing feature.

Pressurized hole as a Stress Reducing Feature:

The output S.I.F with following input parameters such as for the condition for $\mathrm{X}=30 \mathrm{~mm}, \mathrm{Y}=65 \mathrm{~mm}$ and Radius of hole $=25 \mathrm{~mm}$ and also pressure is applied in the stress reducing feature hole and its effect are observed.

Table 3 indicates the reduction in the values of S.I.F. due to applied pressure in the stress reducing feature. Variation of pressure \& corresponding variation in S.I.F. can be observed in this table. 
Table 3 Effect of pressure applied in Stress Reducing Feature Hole

\begin{tabular}{|c|c|c|c|c|c|}
\hline $\begin{array}{c}\text { Sr. } \\
\text { No }\end{array}$ & $\begin{array}{c}\text { X Coordinate } \\
(\mathbf{m m})\end{array}$ & $\begin{array}{c}\text { Y Coordinate } \\
(\mathbf{m m})\end{array}$ & $\begin{array}{c}\text { Radius of } \\
\text { Hole }(\mathbf{m m})\end{array}$ & $\begin{array}{c}\text { Pressure applied in } \\
\text { hole (MPa) }\end{array}$ & $\begin{array}{c}\text { S.I.F } \\
\left(\mathbf{N}-\mathbf{m m}^{-\mathbf{3} / \mathbf{2}}\right)\end{array}$ \\
\hline 1 & 30 & 65 & 25 & 50 & 1029 \\
\hline 2 & 30 & 65 & 25 & 75 & 901.52 \\
\hline 3 & 30 & 65 & 25 & 100 & 774.05 \\
\hline 4 & 30 & 65 & 25 & 125 & 646.58 \\
\hline 5 & 30 & 65 & 25 & 150 & 519.11 \\
\hline 6 & 30 & 65 & 25 & 175 & 391.64 \\
\hline $\mathbf{7}$ & $\mathbf{3 0}$ & $\mathbf{6 5}$ & $\mathbf{2 5}$ & $\mathbf{2 0 0}$ & $\mathbf{2 6 4 . 1 6}$ \\
\hline
\end{tabular}

Thus it is seen that there is very large reduction in the Stress Intensity Factor due to the application of the pressure in the Stress Reducing Feature Hole near the crack tip. Fig. 8 a) shows the application of pressure inside the stress reducing feature hole. Load \& boundary conditions are as in the earlier case.

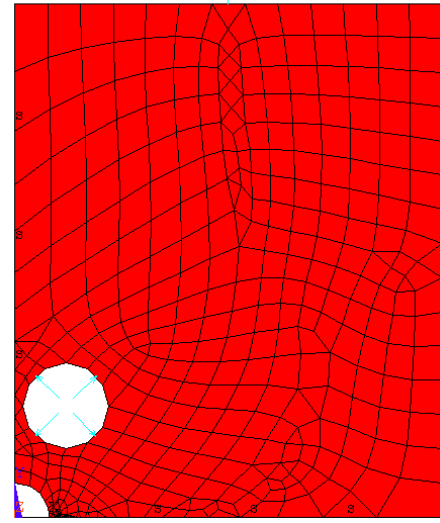

a) Meshed model with load \& boundary conditions

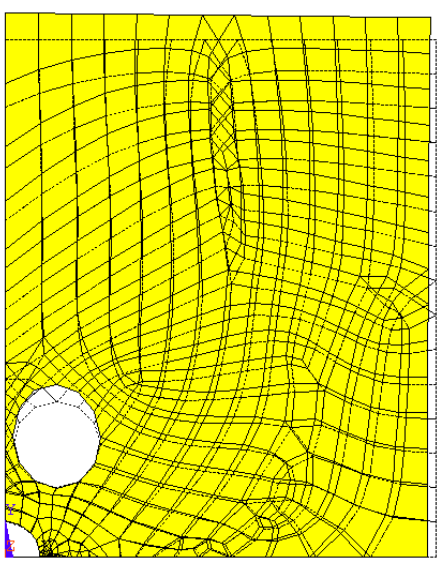

b) Deformed shape

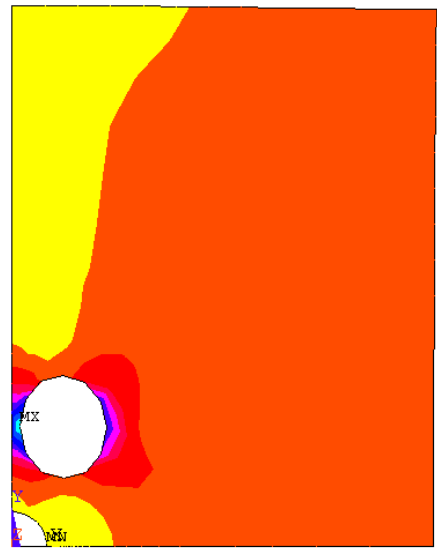

c) Von Mises Stresses

Fig. 8 Pressurized hole as stress reducing feature

Fig. 8 b) shows the deformed shape of the plate. In fig. $8 \mathrm{c}$ ) it s observed that the Von Mises stresses are still reduced due to the use of pressurized hole as a stress reducing feature than only hole as a stress reducing feature.

Table 4 gives the values of the S.I.F. for all three cases i.e. one - without any stress reducing feature, secondwith only hole as a stress reducing feature \& third- with pressurized hole as a stress educing feature.

Table 4 Comparisons of results for Stress Intensity Factor

\begin{tabular}{|c|c|c|c|c|}
\hline $\begin{array}{l}\text { Sr. } \\
\text { No. }\end{array}$ & Analysis of the Model & $\begin{array}{c}\text { Analytical solution } \\
\left(\mathrm{N}-\mathrm{mm}^{-3 / 2}\right)\end{array}$ & $\begin{array}{l}\text { FEM solution } \\
\left(\mathrm{N}-\mathrm{mm}^{-3 / 2}\right)\end{array}$ & Variation (\%) \\
\hline 1 & Model without stress reducing feature hole & 1802.23 & 1834.4 & 1.785 \\
\hline 2 & $\begin{array}{l}\text { Model with a stress reducing feature hole } \\
\text { only }\end{array}$ & -------- & 1283.9 & -------- \\
\hline 3 & $\begin{array}{l}\text { Model with a pressurized stress reducing } \\
\text { feature hole }\end{array}$ & & 264.16 & \\
\hline
\end{tabular}

\section{Conclusions}

Stress analysis of a plate with hole \& cracks emanating from the hole is done. Stress relieving feature circular hole is tried. Also pressure is applied in stress relieving feature hole.

Following are the conclusions.

$>$ Improper location of stress reducing feature hole leads to increase in Stress Intensity Factor.

Reduction in Stress Intensity Factor can be done by drilling holes at proper locations.

$>$ Applying pressure in a hole to be used as stress reducing feature leads to further reduction of Stress Intensity Factor 


\section{Acknowledgements}

We are thankful to Principal \& Management of W.I.T., Solapur to support for this work. We are also thankful to Principal \& Management of MES's COE, Pune for providing platform to present our work.

\section{REFERENCES}

1]. Miloud Souiyah, Abdulnaser Alshoaibi. et al, Stress intensity factor Evaluation for crack Emanating from circular hole using Finite element method, International review of mechanical engineering, 2(4), 2008.

2]. Xiangqiao Yan and Baoliang Liu, Hole Crack Problems in Infinite Plate Subjected to Uniform Internal Pressure" Pressure Vessel Technology, 133(6), 2011

3]. Junping Pu, Effect of defective holes on crack using the boundary element method, Engineering Analysis with Boundary Elements, 30(7), 2006

4]. L. Parnas , O. G. Bilir, Strain gage methods for measurement of opening mode stress intensity factor, Engineering Fracture Mechanics, 55(3), 1996

5]. G.A. Papadopoulos, B. Badaloukaandj, "Experimental Study of the Reduction at Crack Tip Stress Intensity Factor $\mathrm{K}_{\mathrm{I}}$ by Bonded Patches", International Journal of Fracture, 149(2), 2008.

6]. S.T. Pinho, H.B. Martins, P.P. Camanho, M.H. Santare, "Residual Stress Field and Reduction of Stress Intensity Factor in Cold Worked Holes", Theoretical and Applied Fracture Mechanics, 44(2), 2005.

7]. G. C. Sih, Handbook of Stress Intensity Factors, S.I. F. Solutions and Formulas, Bethlehem Institute of Structure and Solid Mechanics, pages 1.2.8.3 [Newman 1969]

8]. T. R. Chandrupatla, A. D. Belegundu, Introduction to Finite Elements in Engineering, Prentice Hall India, 2005 